\title{
Somatic Mutation and CDR3 Lengths of Immunoglobulin $\kappa$ Light Chains Expressed in Patients with Rheumatoid Arthritis and in Normal Individuals
}

\author{
S. Louis Bridges, Jr., ${ }^{\star \|}$ Soo Kon Lee, *\| Maria L. Johnson, ${ }^{* \|}$ John C. Lavelle, ${ }^{5}$ Priscilla G. Fowler, * \\ William J. Koopman, $* \|$ and Harry W. Schroeder, Jr. $\|$ \$1 $* *$ \\ ${ }^{*}$ Division of Clinical Immunology and Rheumatology, ${ }^{\ddagger}$ Division of Pulmonary and Critical Care, ${ }^{8}$ Division of Developmental and \\ Clinical Immunology, Departments of "Medicine and 'Microbiology, and the **Comprehensive Cancer Center, University of Alabama at \\ Birmingham; and the ${ }^{\ddagger \ddagger}$ Birmingham Veterans Administration Medical Center, Birmingham, Alabama 35294-3300
}

\begin{abstract}
Immunoglobulin secretion by plasma cells infiltrating synovial membranes is a prominent feature of RA. Previous analyses of a cDNA library generated from synovium of RA patient $\mathrm{BC}$ revealed immunoglobulin $\kappa$ light chain transcripts with extensive somatic mutation, frequent $\mathbf{N}$ region addition, and unexpected variation in the lengths of CDR3 regions which form the center of the antigen binding site. To determine if these characteristics are present in other individuals, we performed reverse transcription-polymerase chain reaction amplification and sequenced $\geq 10 \mathrm{~V} \kappa$ containing amplicons from nine tissue samples: synovia of three individuals with long-standing RA (including patient BC), PBLs of two of these individuals, and PBLs or splenocytes of four normal individuals. Increased levels of somatic mutation in PBLs appeared to correlate with increased age, which may reflect accumulation of circulating memory cells and/or decreased bone marrow production of naive $B$ lymphocytes. Two of three RA synovial samples and both RA PBL samples exhibited increased proportions of clones with unusual CDR3 lengths. Enrichment for these antibody binding sites could be due to abnormal regulation of the emerging repertoire or to selection for $B$ lymphocytes bearing antibodies of unusual specificity, and may play a role in the pathogenesis of RA. (J. Clin. Invest. 1995. 96:831-841.) Key words: synovium • B lymphocytes • aging • immunoglobulin genes $\bullet$ immunoglobulin variable region
\end{abstract}

\section{Introduction}

Rheumatoid arthritis (RA) is a systemic disease marked by synovial inflammation and hyperplasia that often destroys involved joints $(1,2)$. Infiltration of the synovium by antibody-

S. Louis Bridges, Jr. and Soo Kon Lee contributed equally to this work. Address correspondence to Dr. Harry W. Schroeder, Jr., Division of Developmental and Clinical Immunology, Wallace Tumor Institute 378, University of Alabama at Birmingham, Birmingham, AL 35294. Phone: 205-934-1522; FAX: 205-934-1875. Soo Kon Lee's current address is the Department of Internal Medicine, Yonsei University College of Medicine, C.P.O. Box 8044, Seoul, Korea.

Received for publication 28 October 1993 and accepted in revised form 17 May 1995.

1. Abbreviations used in this paper: CDR, complementarity determining region; D, diversity; FR, framework region; J, joining; RF, rheumatoid factor; TdT, terminal deoxynucleotidyl transferase; V, variable.

The Journal of Clinical Investigation, Inc.

Volume 96, August 1995, 831-841 secreting plasma cells is a characteristic feature of the disease $(3,4)$. This local production of antibody is thought to participate in the pathogenesis of RA, although the exact mechanism(s) of tissue injury remains unclear (2).

Antibodies consist of two heavy chains and two light chains (either $\kappa$ or $\lambda$ ). Each polypeptide chain contains a variable domain for antigen recognition and a constant domain, which is responsible for effector functions. The variable domain is assembled at the DNA level by splicing together variable (V), ${ }^{1}$ diversity ( $D$, heavy chain only), and joining $(J)$ gene segments $(5,6)$. Immunoglobulin variable domains contain three intervals of sequence hypervariability (CDRs) that are separated from each other by four intervals of relatively constant sequence called framework regions (FRs) (for review see reference 7). The $\mathrm{V}$ gene segment encodes CDR1 and CDR2, whereas CDR3 is the product of $\mathrm{V}-(\mathrm{D})-\mathrm{J}$ joining. In the mature protein, the heavy and light chain CDRs are juxtaposed to form the antigen binding site. Because the CDR3 intervals form the center of the antigen binding site, their sequence and structure play a major role in defining antigen specificity of antibodies.

B lymphocytes use both germline and nongermline (somatic) mechanisms to generate antibodies potentially capable of recognizing a tremendously large number of antigens. In the human kappa locus, there are $\sim 28$ potentially functional $\mathrm{V}_{\kappa}$ gene segments that can be grouped into six families based on shared nucleotide sequence homology $(8,9)$. Random combinations of these germline $V_{\kappa}$ gene segments with one of five $\mathrm{J} \kappa$ gene segments can produce a large array of different light chain rearrangements. Somatic mechanisms, however, account for the vast majority of repertoire diversification. Initial variation is focused at the site of heavy chain gene segment splicing (10). Loss of a variable number of nucleotides at the termini of the $\mathrm{V}, \mathrm{D}$, and $\mathrm{J}$ gene segments in association with the addition of nongermline encoded nucleotides ( $\mathrm{N}$ regions) generates a heavy chain CDR3 repertoire that varies tremendously in length, structure, and sequence $(7,10)$.

$\mathrm{N}$ region nucleotides are added to the exposed termini of rearranging gene segments through the activity of terminal deoxynucleotidyl transferase (TdT) $(11,12)$. Expression of TdT is thought to be restricted to the pro-B cell stage, when heavy chain rearrangement occurs. TdT protein is not detectable in cytoplasmic $\mathrm{C} \mu^{+}$pre-B cells, the stage at which immunoglobulin light chain gene segments typically undergo rearrangement $(12,13)$. However, there is substantial evidence that $\mathrm{N}$ region addition occurs in $\mathrm{V} \kappa-\mathrm{J} \kappa$ joins derived from $\mathrm{B}$ cells of normal individuals $(8,14-16)$ as well as from patients with RA $(17,18)$. Despite the presence of $\mathrm{N}$ region addition, rearrangement of $\kappa$ light chain gene segments results in minimal $\mathrm{V} \kappa-\mathrm{J} \kappa$ junctional diversity, largely because of the lack of $D$ gene segments and similar lengths of the five known $\mathrm{J} K$ gene 
segments. The resultant $V_{\kappa}-J_{\kappa}$ joins usually encode either 9 or 10 amino acids (codons 89-97 according to Kabat [19]).

In a previous study, we cloned and sequenced randomly isolated $\kappa$ light chain transcripts from a cDNA library generated from diseased synovium of a patient with long-standing, RFpositive RA (17). Unexpectedly, there was a high proportion of light chains containing $\mathrm{N}$ regions at the $\mathrm{V} \kappa-\mathrm{J} \kappa$ junctions, resulting in uncommon variation in the lengths of CDR3 regions as compared with previous compilations of $\kappa$ light chain sequences. In addition, there were clonally related transcripts in the cDNA library, suggesting that immunoglobulin production in the synovium was antigen driven (20).

With these observations in mind, we sought to determine if expression of $\kappa$ light chain transcripts with unusual CDR3 lengths was specific to this particular sample of RA synovium or was reflective of a more generalized process. We chose to focus on transcripts derived from the V $\kappa$ III family, particularly the gene segment Humkv325. Humkv325 (A27 in Zachau nomenclature [8]) is highly conserved among different individuals in several outbred populations, it is expressed early in fetal life (21), and is a common component of $\mathrm{CD}^{+} \mathrm{B}$ cells. In addition, Humkv325 is frequently expressed in chronic lymphocytic leukemia (for review see reference 22 ) and is often found in $\operatorname{IgM} \kappa$ RF paraproteins $(23,24)$ and RFs from patients with RA $(18,25,26)$. Finally, as mentioned above, the initial RA synovial cDNA library we analyzed contained clonally expanded transcripts. These were derived from Humkv325 and contained CDR3 regions 11 codons long (20).

We PCR amplified cDNA and performed sequence analysis of $\mathrm{V} \kappa$ transcripts expressed in synovium or PBLs of our previously described patient, from two additional individuals with long-standing RA, and from PBLs or spleen cells of four controls. The unusual length distribution of the CDR3 domains expressed in the original patient's synovium was also present in her PBLs. One of the two other individuals with RA demonstrated similar enrichment for $\kappa$ light chains with unusual CDR3 lengths in both synovium and PBL. These findings suggest that $V_{\kappa}$ repertoires expressed in synovial tissue and PBLs of some patients with RA are different from normal individuals, which may have important implications regarding the pathogenesis of RA.

\section{Methods}

Patient characteristics and isolation of synovial cells and PBLs. Clinical characterization of the RA patient we initially studied (patient BC) and the methods used to process the synovial tissue and peripheral blood have been reported previously $(17,20)$. Two additional patients with long-standing RA were studied; synovial tissue was obtained at the time of surgery and peripheral blood was obtained during the postoperative period or at the time of the initial outpatient follow-up visit. The total amounts of IgM, IgA, and IgG from synovial cell culture supernatants were quantitated by ELISA and modifications of a previously described solid-phase RIA (27). Measurements of serum IgM, IgA, and IgG, as well as IgM rheumatoid factor (RF) and IgA-RF were performed by quantitative ELISA (28).

Patient JR, a 60-yr-old white male with a 20 -yr history of RA, underwent right total knee arthroplasty in August 1993. Synovial tissue obtained at the time of surgery yielded a total of $5.8 \times 10^{7}$ cells. Net immunoglobulin production by synovial cells (ELISA results minus cycloheximide control) was $3,529 \mathrm{ng} / \mathrm{ml} \mathrm{IgG,} 691 \mathrm{ng} / \mathrm{ml} \mathrm{IgM}$, and 134 $\mathrm{ng} / \mathrm{ml}$ IgA. A substantial amount of IgM RF was secreted by cultured synovial cells (net $635 \mathrm{ng} / \mathrm{ml}$ ). The serum IgM RF was $164 \mu \mathrm{g} / \mathrm{ml}$ and IgA RF was $12.8 \mu \mathrm{g} / \mathrm{ml}$.

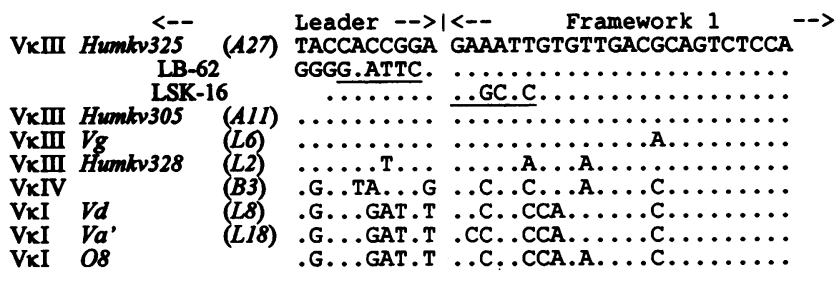

Figure 1. Nucleotide sequences of oligonucleotide primers LSK-16 and LB-62 used to preferentially amplify Humkv325-derived sequences. All sequences, including those of the primers are compared with germline Humkv325, with dots indicating identity. The germline sequences of gene segments represented among the different tissue samples are shown for purposes of comparison. The underlined sequences indicate modifications to encode SacI or EcoRI restriction sites for subcloning.

Synovial tissue from patient AS, a 42-yr-old black female with a 6yr history of RF-positive RA, was obtained at the time of synovectomy of the right elbow. A total of $7.9 \times 10^{7}$ cells was obtained from this synovial tissue. The net synovial cell IgM production was $2,655 \mathrm{ng} / \mathrm{ml}$, IgA $933 \mathrm{ng} / \mathrm{ml}$, and IgG $>10 \mu \mathrm{g} / \mathrm{ml}$. The IgM RF was $886 \mathrm{ng} / \mathrm{ml}$ and IgA RF was $227 \mathrm{ng} / \mathrm{ml}$. The serum IgM RF was $329 \mu \mathrm{g} / \mathrm{ml}$ and IgA $\mathrm{RF}$ was $80 \mu \mathrm{g} / \mathrm{ml}$.

Control tissues analyzed included PBLs of a normal 60-yr-old white female (IT), who served as an age-, sex-, and race-matched control for patient BC, PBLs from a normal 21-yr-old white female (LK), PBLs from a normal 32-yr-old white male (LB), and cadaveric spleen cells from a 49-yr-old white male (SP) without history of autoimmune disease. Mononuclear cells were isolated from spleen or peripheral blood by Ficoll-Hypaque density gradient centrifugation (29).

Generation of $C D N A$ and PCR amplification of $V k$-containing transcripts. The guanidinium isothiocyanate technique was used to isolate total RNA from each sample (30). Oligo $d(T)$ primed first strand cDNA was generated from total RNA as described previously (20), with the exception of synovial tissue from patient BC. Because all of the RNA that had bound to the oligo $d(T)$ column had been used in previous experiments, we generated oligo $d(T)$ primed first strand cDNA from RNA that had been passed through the oligo $d(T)$ column but had failed to bind.

PCR amplifications were performed on 2- $\mu$ l aliquots of first strand cDNA, as described previously (20). PCR conditions were: 25 cycles of denaturation at $94^{\circ} \mathrm{C}$ for $1 \mathrm{~min}$, annealing at $50^{\circ} \mathrm{C}$ for $2 \mathrm{~min}$, extension at $72^{\circ} \mathrm{C}$ for $4 \mathrm{~min}$, with a final extension at $72^{\circ} \mathrm{C}$ for $10 \mathrm{~min}$. PCR amplifications designed to enrich for Humkv325-derived sequences were performed with one of two sense 5' oligonucleotide primers (LSK-16 or LB-62) derived from the leader and FR1 of germline Humkv325. Fig. 1 shows the nucleotide sequences of LSK-16 and LB-62 compared with corresponding regions of germline gene segments. In all but one sample, the antisense $3^{\prime}$ oligonucleotide primer used was LSK-19, derived from the $\mathrm{C} \kappa$ sequence (5'-GCGCCGTCTAGAATTAACACTCTCCCCTGTTGAA- $3^{\prime}$ ). In the case of cadaveric spleen CDNA, the antisense $\mathrm{C} \kappa$ primer used was $\mathrm{H}-170$ (5'-CCAGAATTCAACTGCTCATCAGATGGCGGGAAG-3') (20). To control for possible contamination, mock PCR reaction mixtures lacking template or containing products of the first strand cDNA reaction without reverse transcriptase were prepared. None of the controls contained amplified products visible on ethidium-stained agarose gels or product detected by Southern blot analysis using a $\mathrm{C} \kappa$-specific probe.

Cloning and sequencing of PCR products from Humkv325 amplifcations. Aliquots of PCR products from amplifications with primer LSK16 were blunt ended with large fragment DNA polymerase. PCR products from amplifications with primer LB-62 were digested with EcoRI. Ligation into pUC-19 or pBluescript ${ }^{\circledR}$ was performed using T4 DNA ligase (GIBCO-BRL, Gaithersburg, MD) by standard protocol (31). Plasmids were transformed into TB-1 Escherichia coli by electroporation using a Gene Pulser (Bio-Rad, Hercules, CA). At least $10 \mathrm{C} \kappa$ 


\begin{tabular}{|c|c|c|c|c|c|c|}
\hline \multirow[b]{2}{*}{ Tissue (total number of clones) } & \multicolumn{6}{|c|}{ Number and percentage of clones originating from gene segment } \\
\hline & $\begin{array}{l}\text { Humkv325 } \\
\text { (A27) }\end{array}$ & $\begin{array}{l}V g \\
(L G)\end{array}$ & $\begin{array}{l}\text { Humkv328 } \\
\quad(L 2)\end{array}$ & $\begin{array}{l}\text { Humkv305 } \\
\quad(\text { AII })\end{array}$ & $\begin{array}{l}\text { VkIV } \\
(B 3)\end{array}$ & $\begin{array}{c}\mathrm{V} \kappa \mathrm{I} \\
(L 8, L 18, \text { or } O 8)\end{array}$ \\
\hline BC Syn [62 WF RA] $(n=14)$ & $7(50 \%)$ & $4(29 \%)$ & $2(14 \%)$ & - & - & $1(7 \%)$ \\
\hline $\mathrm{BC}$ PBL [62 WF RA] $(n=15)$ & $7(46 \%)$ & - & $4(27 \%)$ & - & $4(27 \%)$ & - \\
\hline AS Syn [42 BF RA] $(n=11)$ & $5(45 \%)$ & $1(9 \%)$ & $4(36 \%)$ & - & $1(9 \%)$ & - \\
\hline AS PBL [42 BF RA] $(n=10)$ & $3(30 \%)$ & $3(60 \%)$ & $4(40 \%)$ & - & - & - \\
\hline JR Syn [60 WM RA] $(n=14)$ & $9(64 \%)$ & $2(14 \%)$ & - & - & $1(7 \%)$ & $2(14 \%)$ \\
\hline ICT PBL [60 WF normal] $(n=11)$ & $6(55 \%)$ & $2(18 \%)$ & $2(18 \%)$ & - & $1(9 \%)$ & - \\
\hline LB PBL [32 WM normal] $(n=12)$ & $9(75 \%)$ & $3(25 \%)$ & - & - & - & - \\
\hline LK PBL [21 WF normal] $(n=11)$ & $1(9 \%)$ & $6(55 \%)$ & $1(9 \%)$ & - & $2(18 \%)$ & $1(9 \%)$ \\
\hline Spleen [49 WM normal] $(n=10)$ & $9(90 \%)$ & - & - & $1(10 \%)$ & - & - \\
\hline
\end{tabular}

positive colonies from each tissue were sequenced by the dideoxy method (32). Sequencing was performed on both strands of all CDR3 regions. In most cases, double-stranded sequencing was performed on the remaining portions of each $\mathrm{V} \kappa$ domain.

Sequence analysis. The FR and CDR domains of each of the sequences were compared individually to corresponding domains of published human $\mathrm{V} \kappa$ sequences using the computer program SAW (Sequence Analysis Workshop ${ }^{\circledR}$ ) (33). Sequences were assigned to germline gene segments according to highest degree of nucleotide sequence homology. Levels of somatic hypermutation were assessed by comparing the FR1 through CDR3 domains (codons 1-95 according to Kabat [19]) of each complete transcript to the appropriate germline sequence and calculating mean divergence rates for each sample. Truncated clones BCPBL2-1, BCPBL2-6, JRSyn16, and ASPBL29 were not included in the somatic mutation analysis. Nucleotide mismatches at the $3^{\prime}$ end of the $\mathrm{V} \kappa$ gene segment or the $5^{\prime}$ end of the $\mathrm{J}_{\kappa}$ gene segment were assumed to represent $\mathrm{N}$ region addition rather than somatic mutation.

Several clones contained contiguous FR or CDR domains which appeared to be derived from one germline gene segment juxtaposed to downstream domains that were apparently derived from a different germline gene segment (see below). To avoid errors in calculation of levels of somatic hypermutation, clones containing crossover artifacts (see below) and clones that contained truncated $\mathrm{V}_{\kappa}$ domains were not included in the somatic mutation analysis. To avoid bias that could be introduced by including several representatives of the same clone, we included only one representative from each set of identical clones in the somatic mutation, $\mathrm{N}$ region addition, and CDR3 length analyses. Clones JRSyn17 (identical to clone JRSyn15), JRSyn19 (two nucleotide differences from clone JRSyn13, but with an identical $\mathrm{V}_{\kappa}-\mathrm{J}_{\kappa}$ join), JRSyn20 (identical to clone JRSyn13), JRSyn23 (identical to clone JRSyn13 except for one nucleotide in FR4), and LBPBL8 (identical to clone LBPBL7) were thus excluded from the analyses of somatic mutation, $\mathrm{N}$ region addition, and CDR3 length.

Statistical analysis. Differences in the amount of somatic mutation of clones from older and younger individuals and the amount of $\mathrm{N}$ region addition and CDR3 length heterogeneity between patients with RA and normal individuals were analyzed using the Student's $t$ test, Fisher exact test, or $\chi^{2}$ test, as appropriate.

\section{Results}

Germline derivation of $\kappa$ light chains amplified with Humkv325 and $C \kappa$ primers. The majority of transcripts (52\%) amplified with Humkv325 and $\mathrm{C} \kappa$ primers were derived from Humkv325 (A27) (Table I). Most of the remaining clones were derived from two other members of the $\mathrm{V} \kappa \mathrm{III}$ family, $V g(L 6) 19 \%$ and Humkv328 (L2) 16\%. One clone, SP9, was derived from the
V $\kappa$ III gene segment Humk305 (A11) (34). None of the other potentially functional members of the $V_{\kappa}$ III family were represented in this analysis. These findings are consistent with the findings of other investigators, in which the overwhelming majority of expressed $\mathrm{V}_{\kappa} \mathrm{III}$ gene segments is derived from Humkv325, Humkv328, and $V g$ (35). Nine clones (8\%) were derived from the single member $V_{\kappa} \operatorname{IV}$ family $(B 3)(36)$, and four (4\%) were derived from $V_{\kappa} I$ gene segments $V d(L 8), V a^{\prime}$ $(L 18)$, or $O 8(8,37)$. The deduced amino acid sequences of all clones from each of the nine samples are shown in Fig. 2, and the nucleotide sequences of CDR3 regions ( $\mathrm{V} \kappa-\mathrm{J} \kappa$ joins) are shown in Fig. 3. In the three RA synovial samples, there was an increased proportion of $\mathrm{J} \kappa 4$-containing sequences (13 of 35 nonidentical clones, 37\%) compared with 9 of 68 clones (13\%) from other tissues $\left(P=0.01, \chi^{2}\right)$. This increase in $\mathrm{J} \kappa$ 4-containing clones was accompanied by a decrease in the proportion of $\mathrm{J} \kappa 1$-containing sequences in RA synovia ( 7 of $39,18 \%$ ) compared with other tissues ( $28 \%$ of RA PBL, $44 \%$ of normal PBL, and $40 \%$ of normal spleen).

Analysis of clones from the synovial tissue of patient JR revealed the presence of a set of four closely related sequences. Clones JRSyn13, JRSyn20, and JRSyn23 are completely identical to each other. Clone JRSyn 19 has two expressed differences from these three clones, resulting in a glycine at codon 25 in CDR1 and a serine at codon 62 in FR3. Although PCR artifact due to $T a q$ polymerase error cannot be excluded, these may represent a set of clonally expanded sequences in this synovial tissue.

PCR amplifications were performed using an annealing temperature that was well below the calculated melting temperatures of the oligonucleotides to avoid bias toward less mutated Humkv325 cDNAs. Because of the high degree of nucleotide sequence homology among members of the $V_{\kappa}$ III family, the finding of non-Humkv325-derived sequences was not surprising. We found that only four (Humvk325, Humkv328, Vg, and

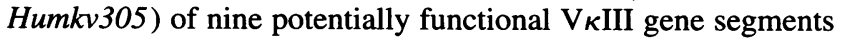
were amplified despite using an annealing temperature low enough to occasionally amplify gene segments from other families $\left(V_{\kappa} I V\right.$ and $\left.V_{\kappa} I\right)$. This restricted number of expressed $V_{\kappa}$ III gene segments is in agreement with other analyses of $\mathrm{V} \kappa$ repertoires $(8,15)$.

Comparison of PCR analysis and CDNA library analysis of the same RA synovial tissue sample. The results of the present 


\section{A. Rheumatoid Arthritis Synovia}

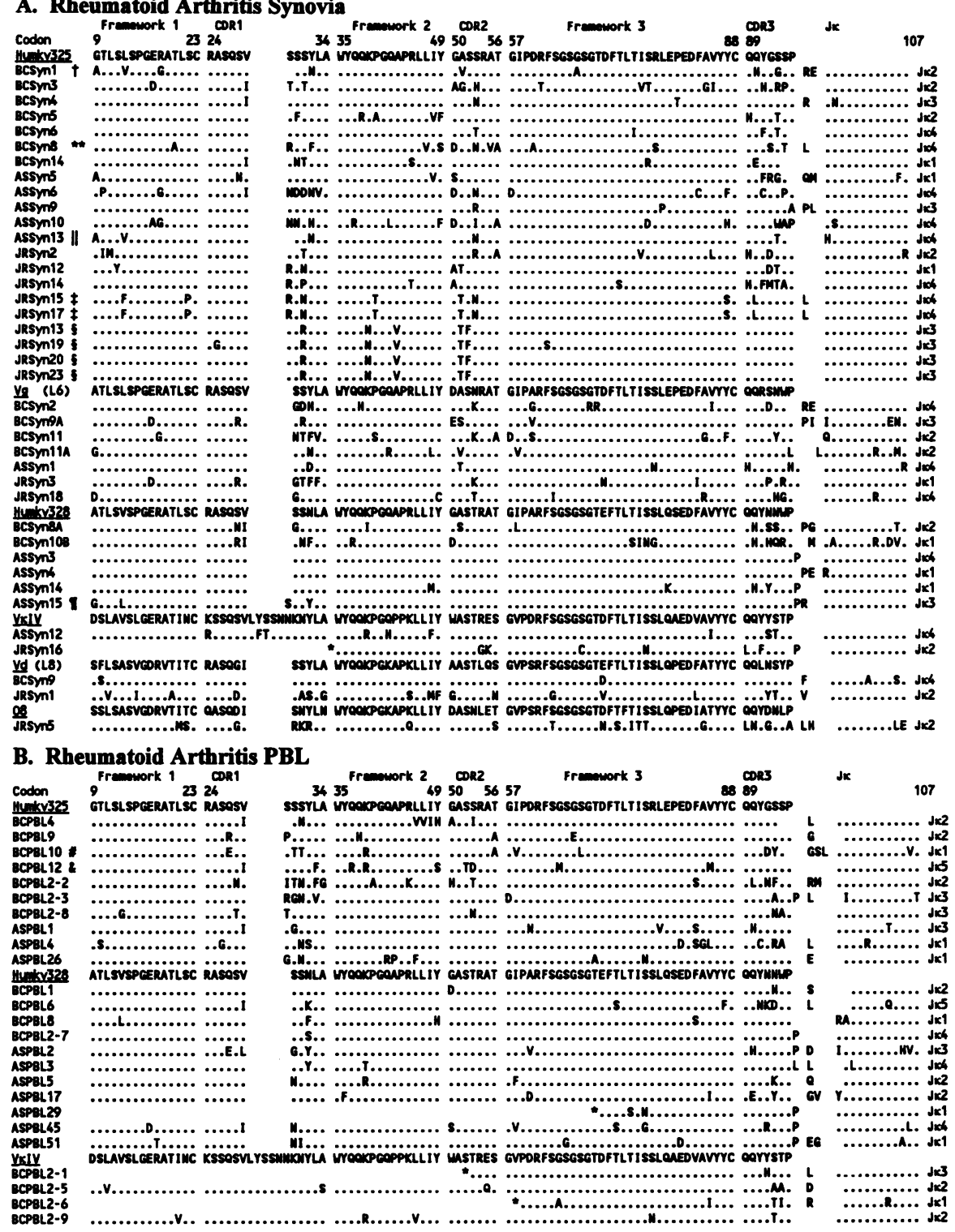

Figure 2. Deduced amino acid sequences of $\kappa$ variable domains amplified from cDNA of different tissue samples. All sequences are compared with the corresponding germline $V_{\kappa}$ gene segment, with a dot indicating identity. Codon numbers are according to Kabat et al. (19). The nucleotide sequences of these clones are available from EMBL/GenBank under accession numbers L40640-L40741. (A) Synovial clones from patients with longstanding RA (BC, AS, and JR). 'The FR1, CDR1, and FR2 domains of clone BCSyn1 appear to be derived from Humkv328; the CDR2 through CDR3 domains, including the $\mathrm{V} \kappa-\mathrm{J} \kappa$ join and $\mathrm{J} \kappa$ gene are identical to Humkv325-derived clone 10S2 (reference 17). ${ }^{*} \mathrm{CDR} 2$ and $\mathrm{FR} 3$ domains of clone BCSyn8 appear to be derived from $\mathrm{Vg}$; all other domains are from Humkv325. "Clone ASSyn 13 contains FR1-FR2 derived from Humkv325; the remaining domains are Humkv328-derived. ${ }^{\ddagger}$ Clone JRSyn 17 is identical to clone JRSyn $15 .{ }^{8}$ Clones JRSyn 20 and JRSyn23 are identical to clone JRSyn 13 .

${ }^{8}$ Clone JRSyn 19 is identical to clone JRSyn13, with the exception of two bases, one in codon 25 (CDR1) and one in codon 62 (FR3). 'FR1 through CDR1 domains of clone ASSyn15 are derived from Humkv328; FR2 through CDR3 are from Humkv325.

'Indicates the 5' end of truncated sequence JRSyn 16. (B) Clones amplified from PBLs of RA patients $B C$ and AS. "The CDR3 of clone BCPBL10 appears to be derived from $\mathrm{V} \kappa \mathrm{IV}$ (see Fig. 3); all other domains are from Humkv325. \&Clone BCPBL12 has an 18-nucleotide insertion between CDR2 and FR3. The deduced amino acid sequence is GAPLAT. *Indicates the 5 ' end of truncated sequences BCPBL2-1 and BCPBL2-6. $(C)$ Clones from PBLs of normal individuals $\mathrm{LB}$, LK, and IT. Dash at codon 59 in FR3 of clone LBPBL1 indicates an apparent deletion. ${ }^{\ddagger \neq}$ FR1 through the $5^{\prime}$ half of FR3 of clone LBPBL5 appear to be derived from $\mathrm{Vg}$, and the 3 ' half of FR3 and the CDR3 domain from Humkv325. ${ }^{\circledR}$ FR1 through CDR2 of clone LBPBL2-3 appear to be derived from Humkv325, and FR3 through CDR3 from Humkv328. (D) Clones from cadaveric spleen (SP) cells from an individual without autoimmune disease. "FR1 through FR2 domains of clone SP7 appear to be derived from Humkv325, CDR2 through CDR3 domains from Vg. "NDR3 domain of clone SP8 appears to be derived from $V g$ (see Fig. 3), all other domains from Humkv325. ${ }^{8} \mathrm{CDR} 3$ domain of clone SP2 appears to be derived from $H u m k v 328$ (see Fig. 3), all other domains from Humkv325.

PCR analysis of synovial cDNA from patient BC were very similar to those obtained by analysis of an unrestricted cDNA library from the same tissue sample. We demonstrated previously that transcripts identical to cDNA clone 10S2 comprised $\sim 5 \%$ of the $\kappa$ transcripts in a non-PCR-amplified cDNA library made from RA synovial tissue of patient $B C(17,20)$. As mentioned above, clone BCSyn 1 from the PCR analysis is identical to clone $10 \mathrm{~S} 2$ from CDR2 through the $\mathrm{V} \kappa-\mathrm{J} \kappa$ join. The finding of one 10S2-like sequence (BCSyn1) among 14 clones isolated by PCR supports our previous approximation of the $5 \%$ frequency of 10S2-like sequences in this synovium (20). Furthermore, three of six ( $50 \%)$ V $\kappa$ III gene segments analyzed in the initial cDNA library had $\mathrm{N}$ region addition, a proportion comparable to that found in the present PCR study of BCSyn
( 8 of 14 clones, 57\%) (Fig. 3). The extent of somatic mutation in the V $\kappa$ III-derived sequences in the cDNA library analysis $(4.4 \pm 2.2 \%, \mathrm{n}=11)$ was remarkably similar to that in the current PCR study $(4.5 \pm 2.0 \%, n=12)$. Finally, 3 of $17(18 \%)$ of randomly chosen $\mathrm{C}^{+}$clones from the original cDNA library and $3(21 \%)$ of 14 synovial clones from the present study contained CDR 3 regions of 11 codons. Thus, the PCR analysis and cDNA library analysis of cells derived from the same synovial tissue sample closely parallel one another, supporting the view that the results of these PCR analyses reflect in vivo immunoglobulin expression.

Although the results of PCR analysis are similar to those of cDNA library analysis, unique PCR artifacts may occur. Despite the use of a relatively low number of PCR amplification 

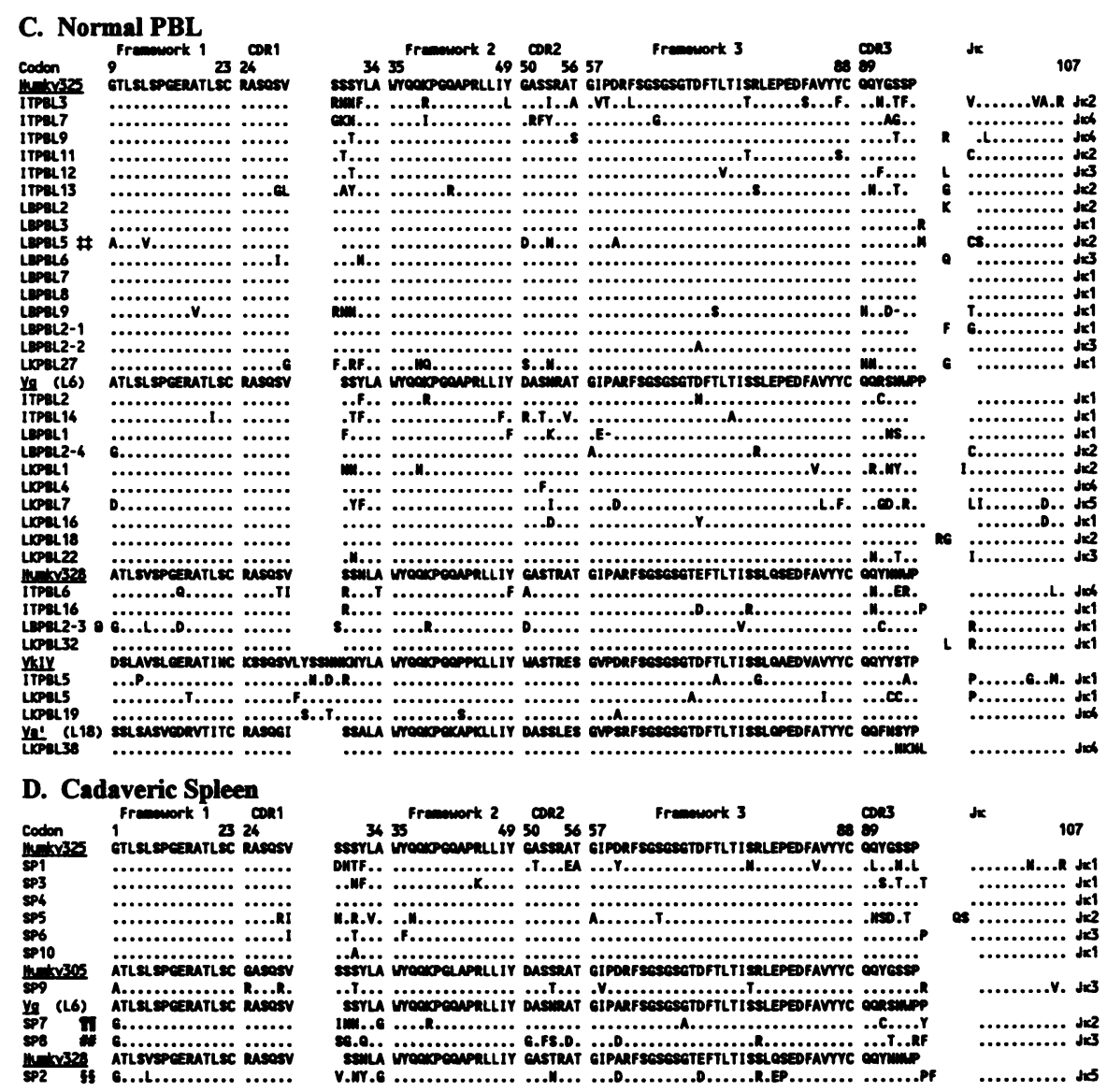

Figure 2 (Continued).

cycles ( 25 cycles), 10 of the 108 clones appeared to contain PCR crossover artifacts (see Figs. 2 and 3). Clone BCSyn1 contains FR1, CDR1, and FR2 domains most homologous to Humkv328, whereas the sequence of CDR2 through $\mathrm{J}_{\kappa}$, including $\mathrm{N}$ region, is identical to clone $10 \mathrm{~S} 2$, a Humkv325-derived clone previously shown by cDNA library analysis to be expanded in this synovial sample (20). Clone BCSyn1, as well as BCSyn8, ASSyn13, ASSyn15, BCPBL10, LBPBL2-3, LBPBL5, SP2, SP7, and SP8 are likely the result of PCR artifact termed jumping PCR (38-40) (see Figs. 2 and 3 for details). Although the evidence for crossover is not as clear, clone BCPBL4 may also contain artifact. BCPBL4 is most homologous to Humkv325 in each FR and CDR domain except CDR1. BCPBL4 does not encode an amino acid at codon 27A in the middle of CDR1 (Fig. $2 B$ ), which suggests it contains a CDR1 domain from $V g$ and may thus represent another example of PCR artifact.

Crossovers artifacts occur when an incomplete product of one amplification cycle serves as a primer for a related sequence, generating a chimeric molecule (38-40). Our sequence analysis software enabled us to easily identify sequences containing crossover events by comparing FR and CDR domains of PCR sequences with corresponding domains from multiple germline gene segments. We cannot exclude the possibility of intragene crossovers, e.g., the presence of a clone that has the $5^{\prime}$ end of a Humkv325-derived sequence and the $3^{\prime}$ end of a different Humkv325-derived sequence. However, because each CDR3 domain was compared with those of all reported germline gene segments, crossover artifact did not affect analyses of
CDR3 length and $\mathrm{N}$ region addition. The reliability of our approach is further enhanced by the knowledge that the $\kappa$ locus has been completely cloned and few sequence polymorphisms have been described.

Somatic hypermutation. The levels of somatic mutation among the transcripts from the different samples as reflected by divergence from progenitor germline genes are shown in Fig. 4 and Table II. Somatic mutation levels did not appear to be affected by disease status, as clones from RA PBL samples were not significantly more mutated than those from controls. The age of the individual, however, did appear to influence the degree of somatic mutation. The transcripts from PBLs of individuals $32 \mathrm{yr}$ of age or younger (LB and LK, $n=20$ ) were significantly less mutated $(1.5 \pm 1.4 \%)$ than those from PBLs of individuals $42 \mathrm{yr}$ of age or older (BC, AS, and IT, $n=30$ ) $(3.2 \pm 2.2 \%)$. This difference reached statistical significance $(P$ $=0.002$, Student's $t$ test). Strikingly, $4(44 \%)$ of $9 \mathrm{~V}_{\kappa}$ transcripts from the PBLs of normal individual LB and 2 (18\%) of 11 clones from LK PBL were completely germline in the $\mathrm{V} \kappa$ region, compared with none of 32 clones from the PBLs of individuals BC, AS, and IT. One clone from spleen contained an unmutated $V_{\kappa}$ gene segment. Synovial clones were very mutated, with mean divergence from germline for the three RA patients ranging from 4.2 to $6.3 \%$ (Table II).

$N$ region addition. The nucleotide sequences of $\mathrm{N}$ regions of each clone are shown in Fig. 3. The percentages of clones with at least one nucleotide of $\mathrm{N}$ region addition were: BCSyn 8 of $14(57 \%)$, BCPBL 10 of 15 (67\%), ASSyn 6 of 11 (55\%), ASPBL 7 of $10(70 \%)$, JRSyn 3 of $10(30 \%)$, LKPBL 6 of 


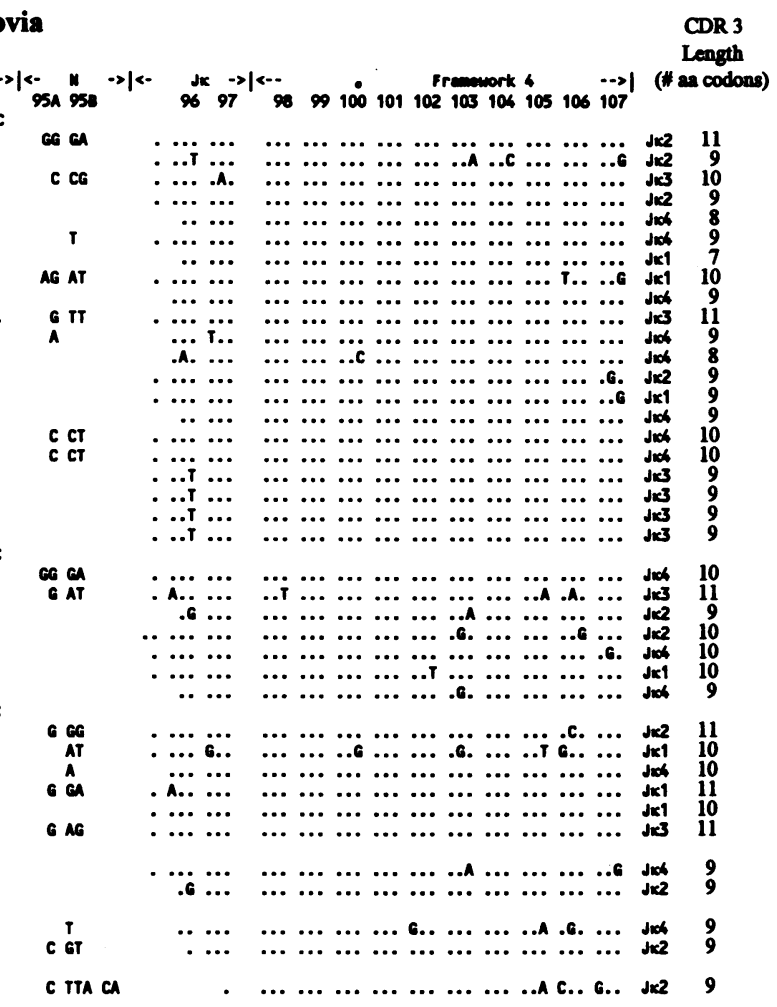

\section{B. Rheumatoid Arthritis PBL}

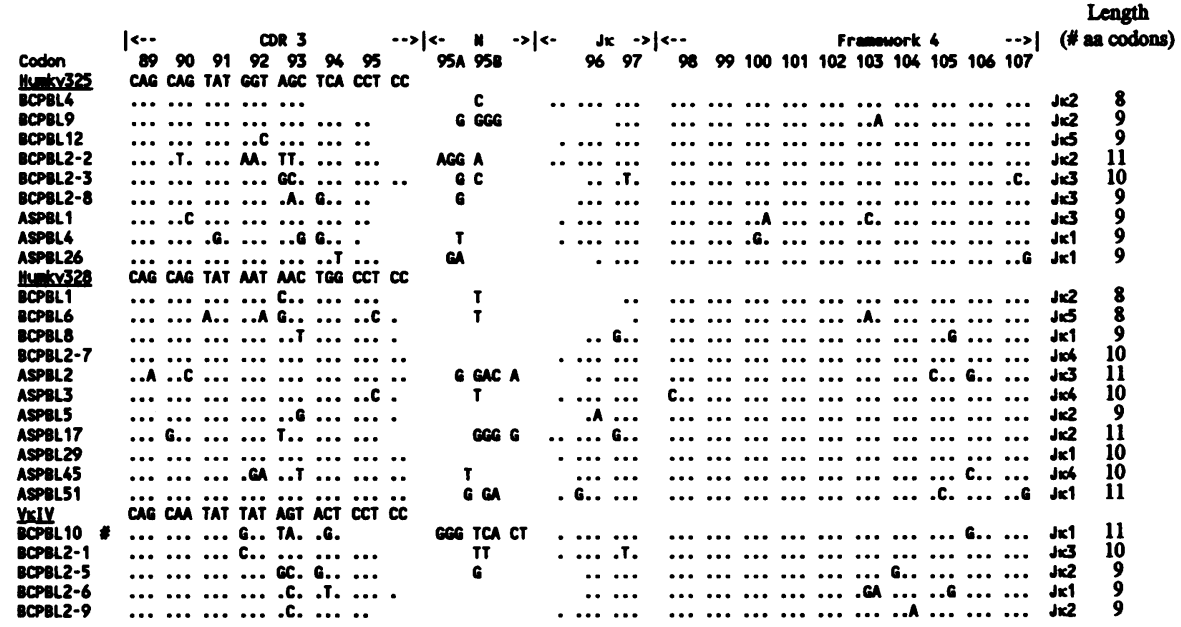

Figure 3. Nucleotide sequences of CDR3 regions of clones shown in Fig. 2. All sequences are compared with the corresponding germline $\mathrm{V} \kappa$ or $\mathrm{J} \kappa$ gene segment, with a dot indicating identity. Nucleotides not assignable to germline $\mathrm{V}_{\boldsymbol{K}}$ or $\mathrm{J}_{\boldsymbol{K}}$ sequence are shown as $\mathrm{N}$ region addition. CDR3 lengths are shown as the number of residues from codon 89 through codon 97 , as assigned by Kabat et al. (19). (A) Synovial clones from patients with long-standing RA (BC, AS, and JR). ( $B$ ) Clones amplified from PBLs of RA patients BC and AS. $(C)$ Clones from PBLs of normal individuals LB, LK, and IT. (D) Clones from cadaveric spleen $(S P)$ cells from an individual without autoimmune disease. See legend for Fig. 2 for explanation of symbols.

$11(55 \%)$, LBPBL 5 of $12(42 \%)$, spleen 5 of $10(50 \%)$, and ITPBL 3 of $11(27 \%)$. The percentages of PBL-derived clones containing $N$ region addition were $68 \pm 2 \%$ (mean \pm standard deviation) for the two RA patients and $41 \pm 14 \%$ for the three normal individuals ( $P=0.04$, Student's $t$ test, one-tailed $)$. Of clones that contained $\mathrm{N}$ region addition, the average number of nucleotides added to each $\mathrm{V} \kappa-\mathrm{J} \kappa$ was $\sim 2.5$ for each of the RA and control tissues.

$C D R 3$ lengths of $V_{\kappa}$ transcripts. The $V_{\kappa}$ repertoires of RA patients demonstrated increased heterogeneity of CDR3 lengths (Fig. 5). Clone BCSyn14 is of interest in that its CDR3 region contains only seven codons. Exonuclease activity resulted in the loss of seven nucleotides from the $3^{\prime}$ terminus of the Humkv325 gene segment of this clone. Clones with unusually long CDR3s ( 11 amino acid codons) were found in 5 of 25
(20\%) transcripts from PBLs of 2 individuals with RA, but in only 1 of $34(3 \%)$ transcripts from PBLs of 3 normal individuals (Fig. $5 \mathrm{~A}$ ). The percentage of PBL-derived clones with CDR3s of 11 amino acids was $13 \%$ for RA patient $B C$ and $30 \%$ for patient AS, for an average of $22 \pm 12 \%$. For the PBL samples of normal individuals, the percentage of clones with CDR3s of 11 codons was $0 \%$ for individual LB, $9 \%$ for individual LK, and $0 \%$ for individual IT, for an average of $3 \pm 5 \%$. The difference between RA and normal with regard to mean percentage of PBL-derived clones containing CDR3s of 11 codons was statistically significant ( $P=0.04$, Student's $t$ test, one-tailed $)$. Unsorted B lymphocytes in peripheral blood, spleen, and inflamed synovium likely represent three distinct cell populations, so direct comparisons may not be appropriate. Therefore, the RA synovial clones and spleen clones were not subjected to statisti- 

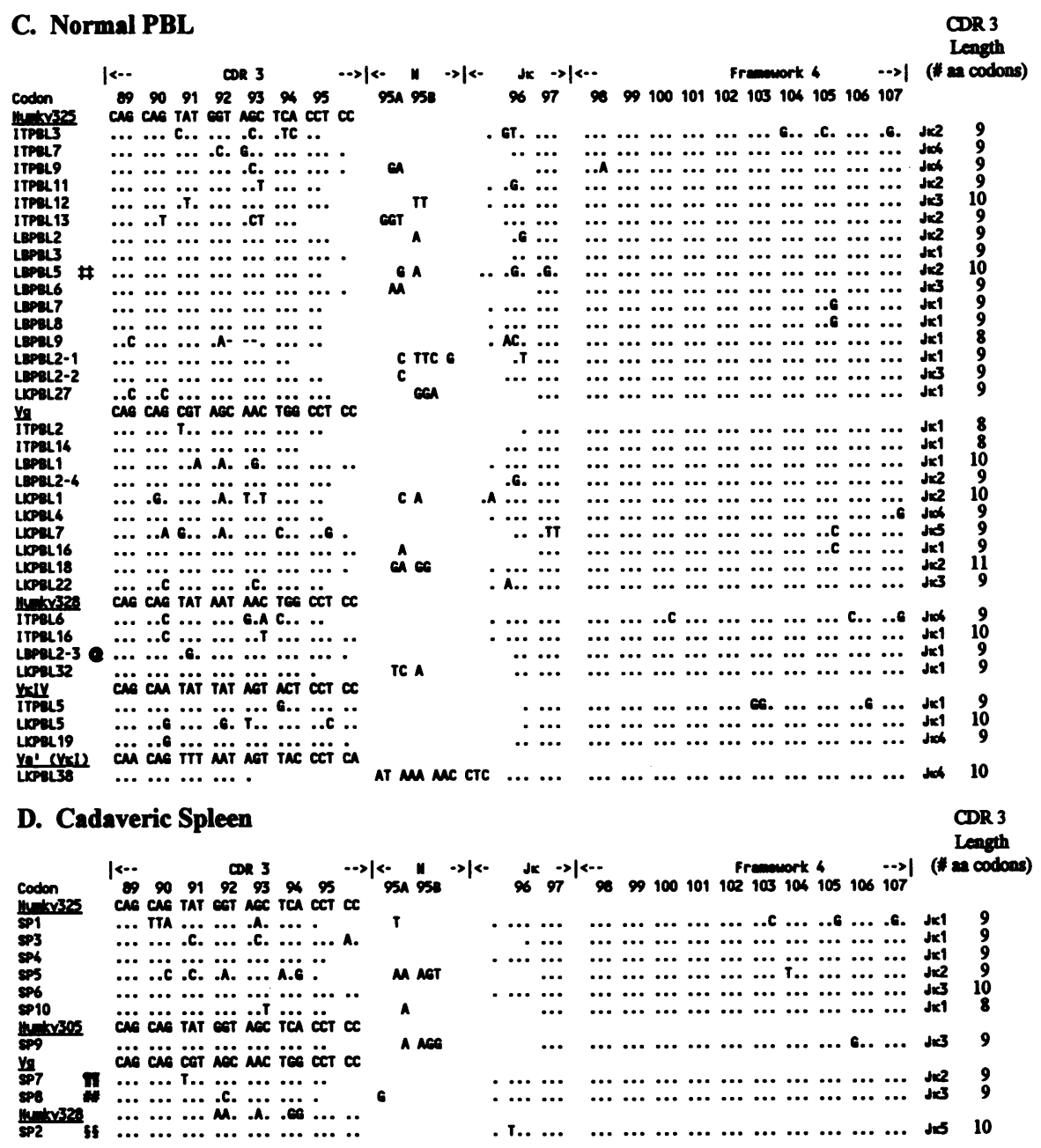

Figure 3 (Continued).

cal analysis regarding CDR3 lengths. Of note, however, the two RA patients whose PBLs were studied also had significant proportions of $V_{\kappa} C D R 3 s$ of 11 amino acids expressed in their synovia: BCSyn, 3 of 14 (21\%); and ASSyn, 3 of 11 (27\%). All clones from the synovium of the remaining RA patient (JRSyn) contained CDR3s of 9 or 10 amino acids. Three of four normal individuals had $\mathrm{V}_{\kappa} \mathrm{CDR} 3$ lengths of exclusively 8,9 , or 10 codons. The fourth control sample, LKPBL, contained one clone with a CDR3 length of 11 codons. In summary, the PBL repertoires of two RA patients and the synovial repertoires of two of three RA patients were enriched for $\kappa$ light chains bearing CDR3 regions of unusual length.

Unusually long CDR3 regions do not seem to be limited to transcripts derived from one particular $V_{\kappa}$ gene segment. Including three clones from our previous analysis (20), we have now isolated a total of $12 \mathrm{RA}$-derived clones containing CDR3 regions of 11 codons. Of these 12 clones, 4 (33\%) are derived from Humkv325, 2 (17\%) from $V g, 4$ (33\%) from Humkv328, 1 from a $V_{\kappa} \mathrm{I}$ gene segment, and 1 from V $\kappa \mathrm{IV}$. Finally, there was not an association between long CDR3 regions and the use of a particular $\mathrm{J}_{\kappa}$ gene segment, as three clones used $\mathrm{J}_{\kappa} 1$, four $\mathrm{J}_{\kappa} 2$, four $\mathrm{J}_{\kappa} 3$, and one $\mathrm{J}_{\kappa} 4$.

\section{Discussion}

$V \kappa$ transcripts from PBLs of younger individuals are less somatically mutated than those from older individuals. We found higher levels of somatic mutation among $\mathrm{V}_{\boldsymbol{\kappa}}$ transcripts derived from PBLs of individuals $42 \mathrm{yr}$ of age or older than among those from individuals $32 \mathrm{yr}$ of age or younger. Many factors such as recent infections, exposure to medications, or normal temporal variation can potentially influence the extent of somatic mutation. We have studied a limited number of individuals at one point in time, so as yet we cannot determine whether or not the finding of an age-related increase in somatic mutation will be generalizable to the entire population. However, a similar age-associated increase in the extent of immunoglobulin sequence mutation has been reported in a study of transcripts bearing $\mathrm{VH}_{\mathrm{H}}$ gene segments from the VH5 family (41).

Differences in the proportions of different $B$ cell subsets between older and younger individuals may, in part, explain the apparent age-associated increase in somatic mutation in PBL $V \kappa s$. Older persons may have higher proportions of circulating $B$ lymphocytes that have been exposed to antigen, which are more likely than naive B cells to express mutated antigen receptors. This hypothesis is supported by several findings. Healthy aged individuals have been found to have fewer circulating B lymphocytes and higher levels of IgG and IgA, but not IgM, than younger individuals (42). In addition, Klein et al. (43) have recently analyzed somatic mutation levels of different peripheral blood $\mathrm{CD}_{19}{ }^{+}$(B cell) subsets from a normal 67-yrold man. They found that $\mathrm{V} \kappa \mathrm{III}$ and $\mathrm{V} \kappa \mathrm{IV}$ clones from $\mathrm{IgM}^{+} \mathrm{IgD}^{+} \mathrm{B}$ cells contained an average of only $0.3 \%$ diver- 

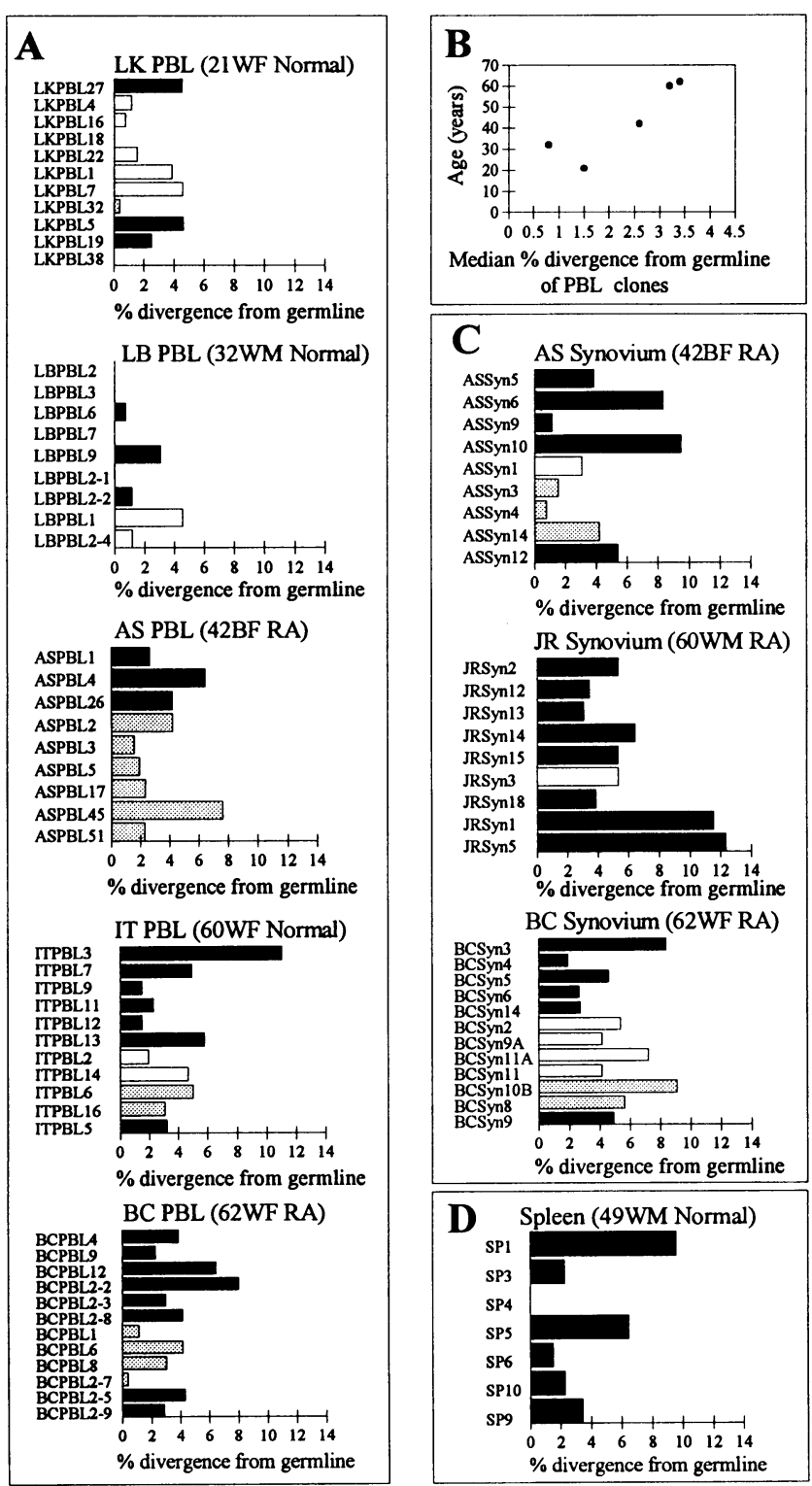

Figure 4. Nucleotide sequence divergence of $\mathrm{V} \kappa$ transcripts from germline. Each bar represents an individual clone from the indicated tissue sample. Germline derivation: black bar, Humkv325; white bar, Vg; dotted bar, Humkv328; grey bar, other Vк. (A) Percent nucleotide sequence divergence from germline of clones from PBLs, arranged by age. $(B)$ Median percent divergence from germline of the five PBL samples in $A$. $(C)$ Percent nucleotide sequence divergence from germline of rheumatoid arthritis synovial clones. $(D)$ Percent nucleotide sequence divergence from germline of clones from cadaveric spleen.

gence from germline. In contrast, clones from $\operatorname{IgM}^{-} \operatorname{IgD}^{-}$(presumably $\mathrm{IgG}^{+}$or $\mathrm{IgA}^{+}$) B cells from the same individual demonstrated an average of $3.9 \%$ divergence from germline (14). Analysis of somatic mutations in $\mathrm{VH}_{\mathrm{H}}$-containing rearrangements PCR amplified from tonsillar and peripheral blood B cells from a 4-yr-old child yielded similar results (43). IgD ${ }^{+}$ tonsillar B cells and $\mathrm{IgM}^{+}$peripheral blood B cells were very homologous to germline ( 0.4 and $0.35 \%$ mutated, respectively). The most mutated subsets of $\mathrm{B}$ cells were tonsillar $\mathrm{IgG}^{+}$germinal center cells and $\mathrm{IgG}^{+} \mathrm{CD}^{-}$peripheral blood B cells, with mean mutation levels of 3.3 and $3.2 \%$, respectively.
Table II. Somatic Mutation of Clones from RA Patients and Controls of Different Ages

\begin{tabular}{|c|c|c|c|c|}
\hline \multirow[b]{2}{*}{ Tissue sample } & \multirow{2}{*}{$\begin{array}{c}\text { No. of } \\
\text { clones } \\
\text { analyzed }\end{array}$} & \multicolumn{3}{|c|}{ Divergence from germline sequence } \\
\hline & & Mean $\pm S D$ & Median & Range \\
\hline & & $\%$ & $\%$ & $\%$ \\
\hline LK PBL (21 WF normal) & 11 & $2.2 \pm 1.9^{*}$ & 1.5 & $0.0-4.6$ \\
\hline LB PBL (32 WM normal) & 9 & $1.2 \pm 1.6^{*}$ & 0.5 & $0.0-4.6$ \\
\hline AS PBL (42BF RA) & 9 & $3.7 \pm 2.1$ & 2.6 & $1.5-7.6$ \\
\hline IT PBL (60 WF normal) & 11 & $4.1 \pm 2.8$ & 3.2 & $1.5-11.0$ \\
\hline PB PBL (62 WF RA) & 12 & $3.6 \pm 2.1$ & 3.4 & $0.4-8.0$ \\
\hline AS Syn (42BF RA) & 9 & $4.2 \pm 3.1$ & 3.8 & $0.8-9.5$ \\
\hline JR Syn (60 WM RA) & 9 & $6.3 \pm 3.4$ & 5.3 & $3.0-12.3$ \\
\hline BC Syn (62 WF RA) & 12 & $5.1 \pm 2.2$ & 4.7 & $1.9-9.1$ \\
\hline Spleen (49 WM normal) & 7 & $3.6 \pm 3.3$ & 2.3 & $0.0-9.5$ \\
\hline
\end{tabular}

Incomplete sequences or those containing PCR crossover artifacts were excluded from analysis. ${ }^{*}$ The $V_{\kappa}$ clones from PBLs of younger individuals LB and LK are less mutated than those from older individuals (RA patients BC and AS, and normal control IT) $(P=0.002$, Student's $t$ test).

Quantitative differences in immunoglobulin mRNA expression among B cells at different stages of differentiation may also be a factor in observed differences in levels of somatic mutation among individuals of different ages. Activated mature B cells have been shown to express approximately twice as much immunoglobulin mRNA as immature B cells (44). Because cDNA analyses reflect mRNA abundance, transcripts from activated cells are more likely to be isolated than transcripts from quiescent B cells. Thus, a decline in de novo B cell production by bone marrow coupled with an increase in the relative proportion of circulating memory and class-switched B cells may account for a higher amount of somatic mutation among the older individuals in this study.

Increased levels of somatic mutation in normal aging individuals may have important ramifications with regard to immune surveillance. Accumulation of memory B cells may enable mature individuals to respond more rapidly to previously encountered common pathogens in their environment. However, such an accumulation could possibly lead to a proportional decrease in the naive repertoire, resulting in decreased ability to respond to novel antigens. This loss of plasticity may theoretically contribute to increased susceptibility of aged individuals to infections.

$\kappa$ light chain repertoires in some patients with autoimmune diseases are enriched for CDR3 regions encoding 11 amino acids. We found that $\mathrm{V} \kappa$ transcripts in two of three RA patients analyzed contain a distinctively high proportion of long CDR3 regions. Data from other investigators corroborate our findings that $\mathrm{V} \kappa \mathrm{CDR} 3$ regions $>10$ codons are rare in normal individuals (Fig. 5). The overwhelming majority $(\sim 96 \%)$ of $\mathrm{V} \kappa$ CDR3s reported in the Kabat compilation (19) contain 8, 9, or 10 amino acid codons (Fig. 5 A). Strikingly, none of these 130 $\mathrm{V} \kappa$ sequences contain a CDR3 region of 11 amino acid codons. In a study of $V_{\kappa}$ transcripts PCR amplified from the peripheral blood lymphocytes of a normal 67-yr-old patient, none of 36 clones contained CDR3 lengths of 11 codons (14). Analysis 


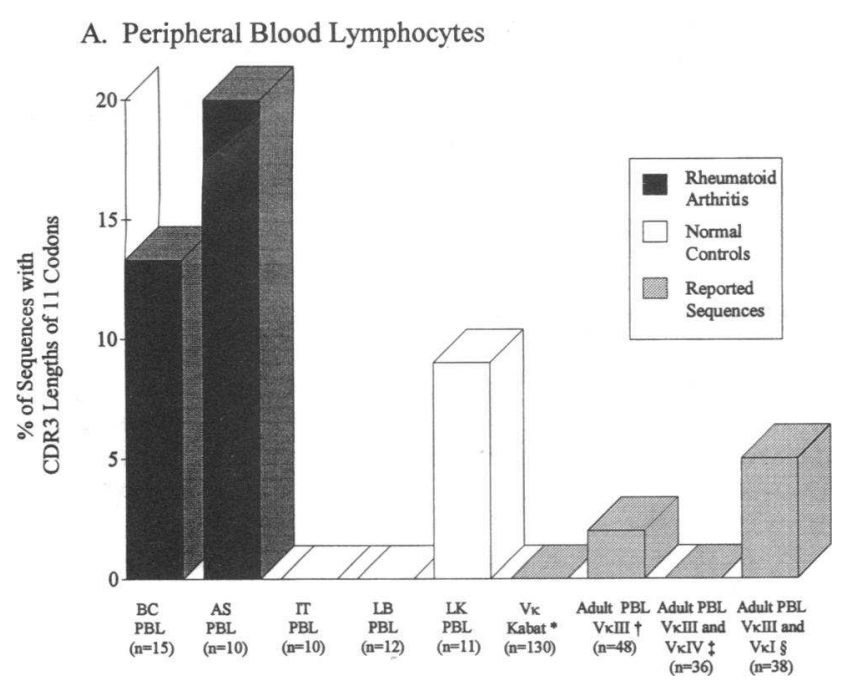

B. Rheumatoid Arthritis Synovia C. Normal Spleen
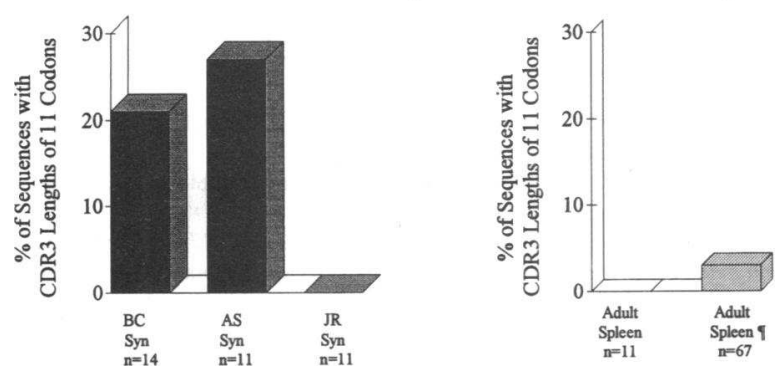

Figure 5. Percentage of $\mathrm{V}_{\kappa}$ clones containing CDR3 lengths of 11 amino acids. *Reported $V_{\kappa}$ sequences in Kabat et al. (19). ${ }^{\dagger}$ Clones from a PCR-amplified cDNA library from PBLs of a normal adult (reference 15 ). ${ }^{\ddagger} \mathrm{Cl}$ lones from $\mathrm{IgM}^{+} / \mathrm{IgD}^{+}, \mathrm{IgM}^{+} / \mathrm{IgD}^{-}$, and $\mathrm{IgM}^{-} /$ $\mathrm{IgD}^{-}$PBLs from a normal 67-yr-old man (reference 14). ${ }^{8} \mathrm{Clones}$ amplified from the PBLs of two normal adult individuals (reference 45). 'Clones from a cDNA library from the spleen of a normal 86-yr-old man (reference 8).

of PCR-amplified cDNA libraries from PBLs of a normal adult demonstrated that only $1(2 \%)$ of $48 \mathrm{~V} \kappa \mathrm{III}$ clones and 1 (11\%) of 9 clonal rearrangements from $\mathrm{CD}^{+} \mathrm{B}$ cells had CDR3 regions of 11 codons (15). Victor et al. (45) amplified VkIII and $\mathrm{V} \kappa \mathrm{I}$ transcripts from PBLs of 2 normal individuals and noted that only 2 of 38 sequences (5\%) had CDR3 domains of 11 codons (45). Although strict comparisons between PBL and spleen B lymphocytes cannot be made, we found no CDR3 domains of 11 amino acid codons from 10 transcripts amplified from cadaveric spleen, and Zachau and colleagues found that only 2 of $66(3 \%)$ clones from a spleen cDNA library had CDR3 regions of 11 codons (8). In summary, $\kappa$ light chains with CDR3 domains of 11 amino acids are found in B lymphocytes from normal individuals, but some patients with RA appear to have repertoires enriched for these long $V_{\kappa} C D R 3 s$.

Our results in RA are in agreement with findings of other investigators who have noted the presence of long $\kappa$ chain CDR3s in some patients with autoimmune diseases. Of 20 $\mathrm{V}_{\kappa} \mathrm{III}-\mathrm{J} \kappa$ joins of polyclonal RFs derived from PBLs and synovial fluid B lymphocytes of a patient with RA, $2(10 \%)$ had CDR3 regions of 11 codons (18). Similarly, 2 (40\%) of $5 \mathrm{~V} \kappa \mathrm{III}$ gene segments ( 1 from SLE PBLs and 1 from RA synovium) contained 11-codon CDR3s $(26,46)$. However, despite the apparent enrichment for 11-codon $V_{\kappa}$ CDR3s in some patients with autoimmune disease, the majority of autoantibodies do not exhibit unusual $\kappa$ light chain CDR3 length. Most CDR3 domains of $\kappa$ light chains of RFs from patients with RA contain 8 , 9, or 10 codons $(25,47-50)$. Although 11-amino acid CDR3s are therefore not required for RF activity, the frequent presence of $\kappa$ chains with 11-amino acid CDR3s in some patients with autoimmune diseases may be a marker for an antibody repertoire that has been abnormally regulated or abnormally activated.

Three factors influence the number of nucleotides at the $\mathrm{V}_{\kappa}-\mathrm{J} \kappa$ join and thus determine the CDR3 length: the site of rearrangement of the $\mathrm{V} \kappa$ gene segment, the site of rearrangement of the $J_{K}$ gene segment, and the presence of $\mathrm{N}$ nucleotides. To delineate the mechanism(s) responsible for generation of CDR3 regions of unusual length in RA, we analyzed patterns of gene segment rearrangement. One of the clones in the present report, BCSyn14 (Fig. 3) has evidence of marked exonuclease activity of the $V \kappa$ gene segment (seven nucleotides removed), resulting in a distinctly unusual CDR3 region of only seven codons. Only two V $\kappa$ III sequences reported in Kabat et al. (19) contain CDR3 regions of less than eight amino acids - one from a multiple myeloma that produced Bence Jones protein (51) and one from an individual with non-Hodgkin's lymphoma (52). Little is known about regulatory control of exonucleolytic loss during gene rearrangement (53).

Variation in the sites of gene rearrangement of the $V \kappa$ to $\mathrm{J}_{\kappa}$ gene segments also influences CDR3 length. The lengths of the five known germline $J_{\kappa}$ gene segments are very similar to one another, with $\mathrm{J}_{\kappa} 2$ containing 38 nucleotides ( 8 in the CDR3 region and 30 in FR4) and $\mathrm{J}_{\kappa} 1, \mathrm{~J}_{\kappa} 3, \mathrm{~J}_{\kappa} 4$, and $\mathrm{J}_{\kappa} 5$ containing 37 nucleotides each ( 7 in the CDR3 region and 30 in FR4). Similarly, most $V_{\kappa}$ gene segments contain 23 nucleotides in the CDR3 region. Analysis of the sites of $V_{\kappa}-\mathrm{J} \kappa$ joining revealed patterns of rearrangement that were consistent throughout all tissues analyzed. Inclusion of 7 nucleotides from the $\mathrm{J}_{\boldsymbol{K}}$ gene segment in conjunction with exonucleolytic loss of 3 nucleotides from the $V_{\kappa}$ gene segment (leaving 20 nucleotides) was the most common pattern (22 of 104 rearrangements). In the absence of $\mathrm{N}$ region addition, this rearrangement yields a CDR3 region of nine codons. The second most common rearrangement, seen in 15 joins, was a contribution of 7 nucleotides from the $\mathrm{J}_{\kappa}$ gene segment and no loss of the $\mathrm{V}_{\kappa}$. sequence (resulting in the inclusion of 23 nucleotides and a CDR3 of 10 codons if there is no $\mathrm{N}$ region addition). 13 joins demonstrated the presence of 5 nucleotides from the $\mathrm{J}_{\kappa}$ and 1 nucleotide lost from the $V_{\kappa}$ (leaving 22 ). This analysis demonstrates that there is more variability in the number of nucleotides removed from the $V \kappa$ than in the number of nucleotides removed from the $J_{\kappa}$ gene segment. Similar consistency in the sites of gene segment rearrangement have been observed in mouse $\kappa$ light chains (54).

Recently, $\mathrm{N}$ region addition has been noted to contribute extensively to the diversity generated at sites of $\mathrm{V}_{\kappa} \rightarrow \mathrm{J}_{\kappa}$ joining. In the present study, normal individuals and RA patients were found to contain a similar proportion of transcripts with $\mathrm{N}$ region addition (Fig. 3). However, despite the frequent presence of $\mathrm{N}$ region addition, the lengths of the vast majority of CDR3s from normal individuals were relatively constant, with $>95 \%$ of $\kappa$ transcripts containing either 9 or 10 amino acids codons. In contrast, the consequences of $\mathrm{N}$ region addition appear to be quite different in some patients with $\mathrm{RA}$, as $\mathrm{V}_{\boldsymbol{\kappa}}$ transcripts containing 11 amino acids in their CDR3s were commonly 
found in synovia and PBLs of two of the three RA patients. These long CDR3s can only be generated through $\mathrm{N}$ region addition, as the germline $\mathrm{V} \kappa$ gene segments and the longest $\mathrm{J}_{\kappa}$ gene segment, $\mathrm{J}_{\kappa} 2$, provide only 31 of the 33 nucleotides required for an 11-amino acid CDR3.

There are several plausible explanations for the presence of nongermline-encoded nucleotides at the V-J junctions of these light chains. Most likely, there is a point during the transition from the pro-B cell to pre-B cell stage at which there is TdT in an amount sufficient to introduce $\mathrm{N}$ regions into the light chain junction. The level of TdT expression in some pre-B cells could be insufficient for detection by staining, but sufficient for addition of $\mathrm{N}$ regions, as has been shown in $\mathrm{T}$ lymphocytes from human fetal thymus (55). Studies using fluorescenceactivated cell sorting have identified a small subpopulation of pre-B cells expressing both nuclear TdT and cytoplasmic $\mu$ heavy chains (56). Alternatively, light chain rearrangement can potentially precede heavy chain rearrangement in normal pro$B$ cells that express TdT. Kubagawa et al. (57) first documented the existence of pro-B cell lines that had undergone $\kappa$ rearrangements at one or both alleles but contained heavy chain loci in either germline configuration or with $\mathrm{DH}-\mathrm{JH}_{\mathrm{H}}$ rearrangement. These $\kappa$-only cell lines appear to represent an alternative pathway of $B$ lineage development in which light chain rearrangement precedes heavy chain rearrangement, presumably in the presence of TdT. Recently, it has been shown that the light chain rearrangements in these $\kappa$-only cell lines may indeed contain $\mathrm{N}$ regions (58). Thus, sequences that contain $\mathrm{N}$ regions in light chains could represent the progeny of this alternative B cell pathway.

Enrichment of the repertoire for $B$ lymphocytes expressing $\kappa$ light chains with unusual CDR3 lengths can potentially expand the diversity of antigens recognized. The CDR3 region is very important with regard to function, as alteration of the $\mathrm{V}_{\kappa}$ $\mathrm{J}_{\boldsymbol{K}}$ junctional sequence can abrogate the ability of antibody to bind antigen (59). In the absence of $\mathrm{N}$ region addition, only eight different amino acids can be generated at the Humkv325$\mathrm{J}_{K}$ splice site, residue 96 according to Kabat (19). However, if nongermline-encoded nucleotides and variation of CDR3 length are allowed, the potential junctional diversity of the $\kappa$ repertoire increases 1,000-fold. Unusually long CDR3 regions may lead to conformational changes that influence heavy chain and light chain pairing (20). We speculate that individuals capable of generating variant CDR3 intervals, such as patients with RA, may be more likely to generate novel antigen binding sites than individuals constrained toward a more conventional light chain repertoire.

$V \kappa$ transcripts with unusual CDR3 lengths may be the result of abnormal gene rearrangement or antigenic selection. There are at least two possible explanations for the enrichment of $\mathrm{V} \kappa$ domains with unusually long CDR3 domains in some RA patients. There may be intrinsic differences in the mechanisms of gene rearrangement in these patients, such as alterations in regulation of TdT or exonuclease, that result in abnormal development of the preimmune repertoire in bone marrow. If so, family members may also express altered repertoires, representing a potential risk factor for the development of RA. An alternative possibility is that in normal individuals there may be selection against normal B cells that by chance contain $\kappa$ chains with unusual CDR3s, with positive selection by antigen and clonal outgrowth of such B cells in some patients with RA. Because of the mounting evidence that RA is an antigen-driven disease $(20,60)$ and the observation that $\kappa$ light chains with CDR3 regions of 11 codons can encode autoantibodies, we favor the hypothesis that enrichment for $\kappa$ light chains with unusual CDR3 intervals is the product of antigenic selection. In either case, it is apparent that the antibody repertoires of some RA patients are different from those of normal individuals.

\section{Acknowledgments}

We thank Jennifer Collins for excellent technical assistance.

This work was supported, in part, by a Veterans Administration Merit Award (W. J. Koopman) and National Institutes of Health grants AR-01867 (S. L. Bridges, Jr.), HL-07553 (M. L. Johnson), AR-03555 (H. W. Schroeder, Jr. and W. J. Koopman), AI-18958 (W. J. Koopman), AI-18745 (W. J. Koopman), AR-20614 (W. J. Koopman), DK40117 (W. J. Koopman), and AI-33621 (H. W. Schroeder, Jr.). S. K. Lee received support from the Faculty Research Fund and the MyungSun Kim Memorial Foundation of Yonsei University College of Medicine.

\section{References}

1. Mellors, R. C., R. Heimer, J. Corcos, and L. Korngold. 1959. Cellular origin of rheumatoid factor. J. Exp. Med. 110:875-886.

2. Harris, E. D., Jr. 1990. Rheumatoid arthritis: pathophysiology and implications for therapy. N. Engl. J. Med. 322:1277-1289.

3. Bankhurst, A. D., G. Husby, and.R. C. Williams, Jr. 1976. Predominance of $\mathrm{T}$ cells in the lymphocytic infiltrates of synovial tissues in rheumatoid arthritis. Arthritis Rheum. 19:555-562.

4. Smiley, J. D., C. Sachs, and M. Ziff. 1968. In vitro synthesis of immunoglobulin by rheumatoid synovial membrane. J. Clin. Invest. 47:624-632.

5. Tonegawa, S. 1983. Somatic generation of antibody diversity. Nature (Lond.). 302:575-581.

6. Meindl, A., H.-G. Klobeck, R. Ohnheiser, and H. G. Zachau. 1990. The $\mathrm{V} \kappa$ gene repertoire in the human germline. Eur. J. Immunol. 20:1855-1863.

7. Kirkham, P. M., and H. W. Schroeder, Jr. 1994. Antibody structure and the evolution of immunoglobulin V gene segments. Semin. Immunol. 6:347-360. 8. Klein, R., R. Jaehichen, and H. G. Zachau. 1993. Expressed human immunoglobulin kappa genes and their hypermutation. Eur. J. Immunol. 23:3248-3271.

9. Schable, K. F., and H. G. Zachau. 1993. The variable genes of the human immunoglobulin kappa locus. Biol. Chem. Hoppe-Seyler. 374:1001-1022.

10. Sanz, I. 1991. Multiple mechanisms participate in the generation of diversity of human H chain CDR3 regions. J. Immunol. 147:1720-1729.

11. Deibel, M. R., L. K. Riley, M. S. Coleman, M. L. Cibull, S. A. Fuller and $\mathrm{E}$. Todd. 1983. Expression of terminal deoxynucleotidyl transferase in human thymus during ontogeny and development. J. Immunol. 131:195-200.

12. Desiderio, S. V., G. D. Yancopoulos, M. Paskind, E. Thomas, M. A. Boss, N. Landau, F. W. Alt, and D. Baltimore. 1984. Insertion of N regions into heavychain genes is correlated with expression of terminal deoxytransferase in B cells. Nature (Lond.). 311:752-755.

13. Alt, F. W., and D. Baltimore. 1982. Joining of immunoglobulin heavy chain gene segments: implications from a chromosome with evidence of three DJH fusions. Proc. Natl. Acad. Sci. USA. 79:4118-4122.

14. Klein, U., R. Kuppers, and K. Rajewsky. 1993. Human IgM+IgD+ B cells, the major $B$ cell subset in the peripheral blood, express $V_{\kappa}$ genes with no or little somatic mutation throughout life. Eur. J. Immunol. 23:3272-3277.

15. Weber, J.-C., G. Blaison, T. Martin, A.-M. Knapp, and J.-L. Pasquali. 1994. Evidence that the VKIII gene usage is nonstochastic in both adult and newborn peripheral $B$ cells and that peripheral CD5+ adult B cells are oligoclonal. J. Clin. Invest. 93:2093-2105.

16. Bridges, S. L., Jr., S. K. Lee, J. Lavelle, W. J. Koopman, and H. W. Schroeder, Jr. 1992. Somatic mutation and N region in VKIII gene segments expressed in rheumatoid arthritis. Clin. Res. 40:820a. (Abstr.)

17. Lee, S. K., S. L. Bridges, Jr., W. J. Koopman, and H. W. Schroeder, Jr. 1992. The immunoglobulin kappa light chain repertoire expressed in the synovium of a patient with rheumatoid arthritis. Arthritis Rheum. 35:905-913.

18. Martin, T., G. Blaison, H. Levallois, and J. L. Pasquali. 1992. Molecular analysis of the $V_{\kappa}$ III-JK junctional diversity of polyclonal rheumatoid factors during rheumatoid arthritis frequently reveals $\mathrm{N}$ addition. Eur. J. Immunol. 22:1773-1779.

19: Kabat, E. A., T. T. Wu, H. M. Perry, K. S. Gottesman, and C. Foeller 1991. Sequences of Proteins of Immunological Interest. U.S. Department of Health and Human Services, Bethesda, MD. 2387 pp.

20. Lee, S. K., S. L. Bridges, Jr., P. M. Kirkham, W. J. Koopman, and 
H. W. Schroeder, Jr. 1994. Evidence of antigen receptor-influenced oligoclonal B lymphocyte expansion in the synovium of a patient with longstanding rheumatoid arthritis. J. Clin. Invest. 93:361-370.

21. Kipps, T. J., B. A. Robbins, and D. A. Carson. 1990. Uniform high frequency expression of autoantibody-associated crossreactive idiotypes in the primary B cell follicles of human fetal spleen. J. Exp. Med. 171:189-196.

22. Schroeder, H. W., Jr., and G. Dighiero. 1994. Clues to the pathogenesis of CLL through analysis of B cell CLL antibody repertoires. Immunol. Today. 15:288-294.

23. Radoux, V., P. P. Chen, J. A. Sorge, and D. A. Carson. 1986. A conserved human germline $V_{\kappa}$ gene directly encodes rheumatoid factor light chains. J. Exp. Med. 164:2119-2124.

24. Crowley, J. J., R. D. Goldfien, R. E. Schrohenloher, H. L. Spiegelberg, G. J. Silverman, R. A. Mageed, R. Jefferis, W. J. Koopman, D. A. Carson, and S. Fong. 1988. Incidence of three cross-reactive idiotypes on human rheumatoid factor paraproteins. J. Immunol. 140:3411-3418.

25. Ezaki, I., H. Kanda, K. Sakai, N. Fukui, M. Shingu, M. Nobunaga, and T. Watanabe. 1991. Restricted diversity of the variable region nucleotide sequences of the heavy and light chains of a human rheumatoid factor. Arthritis Rheum. 34:343-350.

26. Victor, K. D., I. Randen, K. Thompson, O. Forre, J. B. Natvig, S. M. Fu, and J. D. Capra. 1991. Rheumatoid factors isolated from patients with autoimmune disorders are derived from germline genes distinct from those encoding the Wa Po, and Bla cross reactive idiotypes. J. Clin. Invest. 87:1603-1613.

27. Koopman, W. J., R. E. Schrohenloher, S. S. Crago, D. M. Spalding, and J. Mestecky. 1985. IgA rheumatoid factor synthesis by dissociated synovial cells Arthritis Rheum. 28:1219-1227.

28. Alarcon, G. S. R. E. Schrohenloher, A. A. Bartolucci, J. R Ward, A. J. Williams, and W. J. Koopman. 1990. Suppression of rheumatoid factor production by methotrexate in patients with rheumatoid arthritis: evidence for differential influences of therapy and clinical status on IgM and IgA rheumatoid factor expression. Arthritis Rheum. 33:1156-1161.

29. English, D., and B. R. Andersen. 1974. Single-step separation of red blood cells, granulocytes and mononuclear leukocytes on discontinuous density gradients of Ficoll-Hypaque. J. Immunol. Methods. 5:249-252.

30. Chirgwin, J. M., A. E. Przybyla, R. J. MacDonald, and W. J. Rutter. 1979. Isolation of biologically active ribonucleic acid from sources enriched in ribonuclease. Biochemistry. 18:5294-5299.

31. Ausubel, F. M., R. Brent, R. E. Kingston, D. D. Moore, J. G. Seidman, J. A. Smith, and K. Struhl. 1989. Current Protocols in Molecular Biology. John Wiley \& Sons, New York

32. Sanger, F., S. Nicklen, and A. R. Coulson. 1977. DNA sequencing with chain-terminating inhibitors. Proc. Natl. Acad. Sci. USA. 74:5463-5467.

33. Elgavish, R. A., and H. W. Schroeder, Jr. 1993. SAW: a graphical user interface for the analysis of immunoglobulin variable domain sequences. Biotechniques. 15:1066-1071.

34. Straubinger, B., E. Huber, W. Lorenz, E. Osterholzer, W. Pargent, M. Pech, H.-D. Pohlenz, F.-J. Zimmer, and H. G. Zachau. 1988. T he human Vא locus. Characterization of a duplicated region encoding 28 different immunoglobulin genes. J. Mol. Biol. 199:23-34.

35. Cox, J. P., I. M. Tomlinson, and G. Winter. 1994. A directory of human germ-line V kappa segments reveals a strong bias in their usage. Eur. J. Immunol. 24:827-836.

36. Klobeck, H.-G., G. W. Bornkamm, G. Combriato, R. Mockikat, H.-D. Pohlenz, and H. G. Zachau. 1985. Subgroup IV of human immunoglobulin $\kappa$ light chains is encoded by a single germline gene. Nucleic Acids Res. 13:6515-6529.

37. Pech, M., H.-R. Jaenichen, H.-D. Pohlenz, P. S. Neumaier, H.-G. Klobeck, and H. G. Zachau. 1984. Organization and evolution of a gene cluster for human immunoglobulin variable regions of the kappa type. J. Mol. Biol. 176:189-204.

38. Campbell, M. J., A. D. Zelenetz, S. Levy, and R. Levy. 1992. Use of family specific leader region primers for PCR amplification of the human heavy chain variable region gene repertoire. Mol. Immunol. 29:193-203.

39. Pääbo, S., R. G. Higuchi, and A. C. Wilson. 1989. Ancient DNA and the polymerase chain reaction. J. Biol. Chem. 264:9709-9712.

40. Pääbo, S., D. M. Irwin, and A. C. Wilson. 1990. DNA damage promotes jumping between templates during enzymatic amplification. J. Biol. Chem. 265:4718-4721.

41. Cai, J., C. Humphries, C. Lutz, and P. W. Tucker. 1992. Analysis of VH251 gene mutation in chronic lymphocytic leukemia (CLL) and normal Bcell subsets. Ann. NY Acad. Sci. 651:384-392.

42. Paganelli, R., I. Quinti, U. Fagiolo, A. Cossarizza, C. Ortolani, E. Guerra P. Sansoni, L. P. Pucillo, E. Scala, E. Cossi, L. Bertollo, D. Monti, and C. Franceschi. 1992. Changes in circulating B cells and immunoglobulin classes and subclasses in a healthy aged population. Clin. Exp. Immunol. 90:351-354.

43. Klein, U., R. Kuppers, and K. Rajewsky. 1994. Variable region gene analysis of B cell subsets derived from a 4-year-old child: somatically mutated memory B cells accumulate in the peripheral blood already at young age. J. Exp. Med. 180:1383-1393.

44. Kelley, D. E., and R. P. Perry. 1986. Transcriptional and posttranscriptional control of immunoglobulin mRNA production during B lymphocyte development. Nucleic Acids Res. 14:5431-5447.

45. Victor, K. D., and J. D. Capra. 1994. An apparently common mechanism of generating antibody diversity: length variation of the VL-JL junction. Mol. Immunol. 31:39-46.

46. Pascual, V., K. Victor, I. Randen, K. Thompson, M. Steinitz, O. Forre, S. M. Fu, J. B. Natvig, and J. D. Capra. 1992. Nucleotide sequence analysis of rheumatoid factors and polyreactive antibodies derived from patients with rheumatoid arthritis reveals diverse use of VH and VL gene segments and extensive variability in CDR-3. Scand. J. Immunol. 36:349-362.

47. Weisbart, R. H., A. L. Wong, D. Noritake, A. Kacena, G. Chan, C. Ruland, E. Chin, I. S. Y. Chen, and J. D. Rosenblatt. 1991. The rheumatoid factor reactivity of a human IgG monoclonal autoantibody is encoded by a variant $\mathrm{V}_{\kappa} \mathrm{II} \mathrm{L}$ chain gene. J. Immunol. 147:2795-2801.

48. Gause, A., R. Kuppers, and R. Mierau. 1992. A somatically mutated $\mathrm{V} \kappa \mathrm{IV}$ gene encoding a human rheumatoid factor light chain. Clin. Exp. Immunol. 88:430-434.

49. Deftos, M., T. Olee, D. A. Carson, and P. P. Chen. 1994. Defining the genetic origins of three rheumatoid synovium-derived IgG rheumatoid factors. $J$. Clin. Invest. 93:2545-2553.

50. Youngblood, K., L. Fruchter, G. Ding, J. Lopez, V. Bonagura, and A. Davidson. 1994. Rheumatoid factors from the peripheral blood of two patients with rheumatoid arthritis are genetically heterogeneous and somatically mutated. J. Clin. Invest. 93:852-861.

51. Prelli, F., D. Tummolo, A. Solomon, and B. Frangione. 1986. Novel human light chain $\mathrm{V} \kappa$ segment: serologic and structural analyses of the $\kappa$ III-like Bence Jones protein and IgG $\kappa$ light chain Ree. J. Immunol. 136:4169-4173.

52. Pratt, L. F., L. Rassenti, J. Larrick, B. Robbins, P. M. Banks, and T. J. Kipps. 1989. Ig V region gene expression in small lymphocytic lymphoma with little or no somatic hypermutation. J. Immunol. 143:699-705.

53. Kenter, A. L., and J. Tredup. 1991. High expression of a $3^{\prime} \rightarrow 5^{\prime}$ exonuclease activity is specific to B lymphocytes. Mol. Cell. Biol. 11:4398-4404.

54. Ramsden, D. A., C. J. Paige, and G. E. Wu. 1994. $\kappa$ light chain rearrangement in mouse fetal liver. J. Immunol. 153:1150-1160.

55. George, J. F., Jr., and H. W. Schroeder, Jr. 1992. Developmental regulation of $\mathrm{D} \beta$ reading frame and junctional diversity in $\operatorname{TCR} \beta$ transcripts from human thymus. J. Immunol. 148:1230-1239.

56. Nishimoto, N., H. Kubagawa, and M. D. Cooper. 1991. Comparison of pre-B cell differentiation in normal and X-linked agammaglobulinemia (XLA) individuals. Fed. Proc. 5:1346a. (Abstr.)

57. Kubagawa, H., M. D. Cooper, A. J. Carroll, and P. D. Burrows. 1989 Light-chain gene expression before heavy-chain gene rearrangement in pre-B cells transformed by Epstein-Barr virus. Proc. Natl. Acad. Sci. USA. 86:2356-2360.

58. Schroeder, H. W., Jr., P. D. Burrows, M. D. Cooper, and H. Kubagawa 1992. $\mathrm{N}$ region addition and unusual CDR3 length distributions in $\kappa$-chain only pre-B cells. J. Cell. Biochem. S17B:235. (Abstr.)

59. Ruff-Jamison, S., and J. Glenney. 1993. Requirement for both $\mathrm{H}$ and L chain $\mathrm{V}$ regions, $\mathrm{VH}$ and $\mathrm{V}_{\kappa}$ joining amino acids, and the unique $\mathrm{H}$ chain $\mathrm{D}$ region for the high affinity binding of an anti-phosphotyrosine antibody. J. Immunol. 150:3389-3396.

60. Ermel, R. W., T. P. Kenny, P. P. Chen, and D. L. Robbins. 1993. Molecular analysis of rheumatoid factors derived from rheumatoid synovium suggests an antigen-driven response in inflamed joints. Arthritis Rheum. 36:380-388. 